\title{
Awareness and perceptions of available Major programs by first year Zayed University students
}

\author{
David J. Gallacher, Angela Skuba, Roudha Al-Bahri \\ Zayed University, UAE
}

\begin{abstract}
In recent years there has been a large increase of Higher education options in the United Arab Emirates. Emirati school leavers must choose among newly established institutions that provide unproven qualifications, at the same time as their society undergoes a rapid transformation. Online surveys were administered to female Emirati students in the first $(n=407)$ and second $(n=188)$ semester of the Zayed University general education program, to investigate entering student awareness and perceptions of the seven majors available. Respondents indicated they were motivated by a desire to learn, and had selected their institution for its high academic standards. Half thought they had already decided their major, and while most felt they had made the decision themselves, they were influenced mostly by their immediate family members. Business was ranked highest for potential salary and job availability, and was second only to International Studies for potential social status. All other majors effectively compete with Business for students. Student awareness of Health Sciences and International Studies lagged behind other majors, indicating a need for promotion and/or rebranding. Respondents expressed a clear desire for the introduction of Engineering, Medicine and Law to the course offerings.
\end{abstract}

\section{Introduction}

Higher Education for citizens of the United Arab Emirates has strongly emphasized graduate employment during the last decade. This was perhaps a response to reports that Emirati study choices were mismatched to market demands. For example, between 2000 and 2003, two thirds of Emirati graduates had studied arts, education and religion, while the other third studied engineering, medicine and sciences (IMF, 2005); the ratio among expatriates was reversed. In the public secondary education system, students can choose an arts stream or a sciences stream, with the former being widely perceived as an easier option. Currently, around $60 \%$ of students choose arts, and the trend is increasingly toward arts (Tedad, 2006), though this might be significantly influenced by an increase in private school education. Education is often valued for reasons of social status rather than economic value, despite the fact that salary is an important motivator for changing jobs (Nelson, 2004). It is also valued by many women as a means to escape boredom from an existence within the home (Crabtree, 2007).

In defense of student choices, many of the education and career options currently available within the UAE did not exist even ten years ago. These new courses and careers are therefore not proven through tradition and are not familiar to many families, and role models that students can directly relate to may be lacking (Walters et al., 2008). 
Several theoretical models have been proposed in the last half century to describe the transition from school to career. Among the most influential of these are the personality based Holland's Career Typology (Holland, 1997), and the values-based Social Cognitive Career Theory (Lent, Brown, \& Hackett, 1994). The former describes career choices in terms of six base personalities (realistic, investigative, artistic, social, enterprising, conventional) and though widely supported, it has been criticized for gender bias, since women tend to be classified into one of three personalities (artistic, social or conventional). The latter theory, also widely cited and supported, describes career choices in terms of Social Cognitive Theory (Bandura, 1977). It argues that people make career choices according to four basic elements: being self-efficacy (am I able to), outcome expectations (what are the consequences of), goals (do I really want to) and contextual supports and barriers (what are the environmental / social effects of). Student self-efficacy can be narrowed to academic self-concept, which limits the element to a belief in one's own academic ability. The research reported here is part of a larger project examining Emirati students 'educational and career choices. Its purpose was to evaluate the awareness and perceptions that entering Baccalaureate students have of the different majors available at Zayed University. Awareness of Major programs is arguably a component of the 'contextual supports and barriers' element of the Social Cognitive Career Theory, though is probably better described as a precondition: if students are not aware of a major, or do not understand what it trains them for, they are unlikely to select it. Perceptions of Major programs relates primarily to the 'outcome expectation' element. For this study, we assume that student perceptions of a major are primarily influenced by their perception of the careers that could follow the major.

\section{Education in the United Arab Emirates}

Westernized models of education have appeared only recently in the UAE: the first school, Qassemia School, was opened in 1953-54 in Sharjah. Education systems within the seven Emirates were developed locally until Federation in 1971, when responsibility was delegated to the Ministry of Education and Youth (Al Taboor, 2008). The literacy rate has since risen from around $20 \%$ at Federation (Walters et al., 2008) to the current estimate of 91\% (Tedad, 2006).

Higher education began with the formation of the United Arab Emirates University, situated in Al Ain, which took its first students in Fall 1977. Technical and vocational education was then introduced across multiple campuses throughout the seven Emirates, with the opening of the Higher Colleges of Technology in 1988. Zayed University opened to female students in 1998 on two campuses, Abu Dhabi and Dubai, in an effort to provide university qualifications that were more aligned to market requirements. In addition, many private universities have opened throughout the UAE such that the country can now boast the presence of approximately 80 higher education institutions, depending on the strictness of the definition used. All but a handful of these private institutions have a tiny enrolment of fewer than 50 students.

This proliferation of institutions has translated into a leap in the number of citizens that have received a post-secondary education, and also to the range of study options. At federation in 1971 the UAE had two university trained citizens, both of them male, but today there are around 67000 . There is a common perception in the UAE that Emirati women are far more educated than Emirati men. There is certainly a much higher enrolment of women in the federal higher education institutions: Zayed University, UAE University, and Higher Colleges of Technology, all of which provide a gender separated environment in most of their classes. From 2000 to 2003, 84\% of graduates from these institutions were women (IMF, 2005). However according to census data, there is little difference between the genders in qualification earned. Women hold $54 \%$ of university degrees, but only $33 \%$ of postgraduate degrees, and women comprise $66 \%$ of the $8.8 \%$ of the population that remains illiterate (Tedad, 2006).

Gallacher, D., Skuba, A. \& Al-Bahri, R. (2010). Awareness and perceptions of available Major programs by first year Zayed University students. Learning and Teaching in Higher Education: Gulf Perspectives, 7(1). 
The federally funded Zayed University (ZU) was founded in 1998 by H.E. Shaikh Zayed bin Sultan Al Nahyan with the expressed purpose of educating Emirati women. It has since opened its doors to men and to non-Emirati women, though it remains primarily focused on Emirati women. It currently offers seven majors (Art and Design, International Studies, Health Sciences, Business Sciences, Communication and Media Sciences, Education, and Information Technology), two joint majors (Information Systems and Technology Management, and Technology in Education), and four minors (English Literature, Applied Mathematics, Applied Psychology, and Communication and Media Sciences). Students must complete 42 credit hours, taking approximately three semesters, of foundational and liberal arts courses before entering their major. During these eighteen months, students are assigned an advisor who assists them to develop academically, adapt to university life, and to select their major. Therefore in this study, any reference to a student's major relates to the major that the student has indicated a preference for, which is not necessarily the major they eventually take. Future research in this project will track these students to see how their choice of major develops and changes as their tenure at the University extends and as they progress through their advising and academic development classes.

\section{Methods}

Two online surveys were administered to ZU female students in the first three weeks of the 2009 Fall semester across campuses in Abu Dhabi and Dubai, one each to students in their first and second semester of study. Males were excluded because the current group of 24 students are being offered just one major and are already employed by the federal army. Some female non-Emirati students might have completed the surveys, but they comprise just $0.7 \%$ of the first year student population, so their influence is minimal. The first semester survey focused on their reasons for entering university, their awareness of the major programs offered at the university, and how they rated each major. The second semester survey focused on some of the influences on their future choice of a major, and their expectations of their future careers and success. Hence, most results reported here stem from the first semester study, but sources of influence were obtained from the second semester study. Questions had been divided among surveys, firstly to limit the size of individual surveys, and secondly because it was more appropriate to investigate influences on student choices after students had had exposure to majors education within the university. There were 407 and 188 valid responses respectively, but 59 respondents of the first survey were second semester students, enabling us to test the completion of one semester as an effect. Survey questions were presented in both English and Arabic, and responses were accepted in both languages. The surveys comprised both open and closed-ended questions. Participants were recruited in their advising and academic development class, which all students are required to take, and thus the sample should include an accurate representation of Zayed University students in terms of demographic and social factors. However, as the survey only included students in their first year of study, it must be noted that these results may not apply to students in later stages of their university careers. In order to obtain informed consent, a brief description of the survey, its purpose, and the possible methods of dissemination of results was presented at the beginning of each survey. This description was followed by a yes/no question of whether the students agreed to participate in the research project.

Data was analyzed using SPSS 16.0. Questions were analyzed using chi-square tests of independence, on data that had been reduced to binary form (e.g.; major first choice $=$ Business $/$ major first choice $=$ not Business). 


\section{Findings}

\section{Choosing Higher Education}

When students were asked why they decided to pursue higher education, the most prevalent responses were that they wanted to learn (43\%), and they wanted a good job (26\%). Salary, friends, and family were all relatively minor influences on their decision making. Students interested in Education were a unique group in that more students were motivated by job availability than by wanting to learn. Fewer than $1 \%$ of respondents chose 'something to do' as a reason for entering University. This appears to contradict a previous study in which women were observed to frequently choose education to escape boredom (Crabtree, 2007).

When asked why they chose Zayed University over other higher education institutions, two thirds (67\%) of all respondents selected 'high academic standards'. Eighty four percent said they would have attended another university if the Zayed University option were unavailable. Prospective Business students were more likely than others to select the University for academic reasons $(p=0.025)$, whereas prospective Art \& Design students were more likely than others to select the University for the major offered $(p=0.012)$. Only $4 \%$ of respondents cited safety as a reason for choosing Zayed University, which suggests that the gender separated environment with a secured perimeter is not considered important by the students. Of course, parents might value safety and cultural appropriateness more than their daughters do.

\section{Choosing a Major}

Students were asked to list up to four majors they were considering, as well as the factors they believed would most influence their decision. Almost half (47\%) of 392 respondents identified just one choice, indicating that they have entered the University with a clear expectation of what major they want to take. Personal interest was rated a much larger influence on choice of major than family, job availability, status or salary, which is consistent with previous research (Walters et al., 2008). However, students attending the Dubai campus were more likely to choose a major without their families' support than students in Abu Dhabi. When asked who has the greatest influence on their choice of a major, most participants (76\%) mentioned a family member, even though respondents had previously attended college presentations. Parents had the strongest influence (fathers only slightly more than mothers), then sisters, then friends (Figure 1). This reliance on parental influence is consistent across cultures (Archer, Hutchings, \& Ross, 2003). However, the strong nurturing role of British mothers toward their daughters' educational choice (Brooks, 2004) appears more evenly distributed among mothers, fathers and sisters in Emirati society. 
Figure 1: People who have had the strongest influence on second semester students' choice of major $(n=188)$. Respondents could nominate up to three people. Green bars contain summary data of red bars.

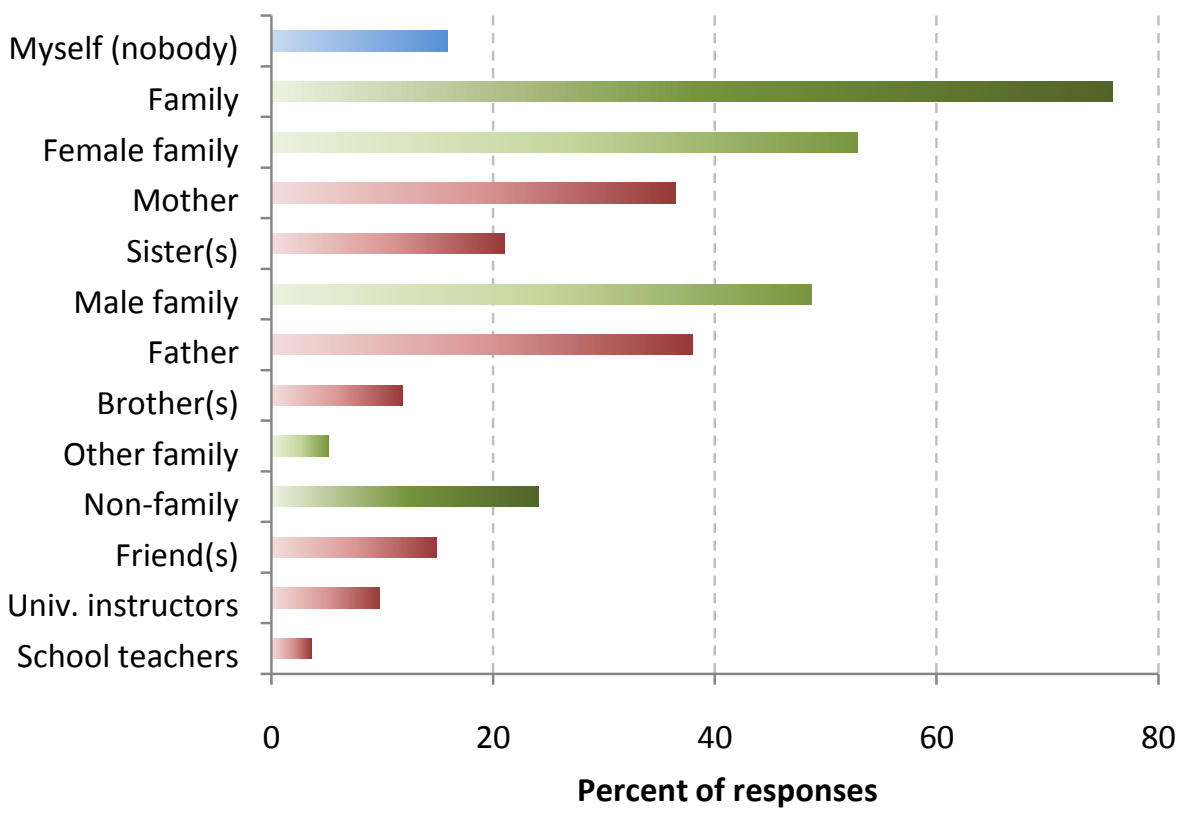

\section{Awareness of available Major programs}

Student awareness of the different majors was gauged by asking first-semester respondents to list up to ten courses of study they believed existed at Zayed University. Only $2 \%$ of students listed all seven majors, or at least one concentration from each major, and $10 \%$ of students listed none. On average, students listed 3.3 majors. Business was the best known major (Figure 2), listed by $70 \%$ of all students, while most other majors were listed by approximately $50 \%$ of students. There is a much lower awareness of Health Science and International Studies, but the students who could name these were more likely to name a specialization within the major (e.g. Nutrition, Politics, Environmental Health). The specializations of Education, Information Technology, and Media \& Communication were hardly mentioned, indicating that students were much more aware of the specializations of Business, and Art \& Design. A small number of students listed majors that are not offered by the University, such as Engineering (2\%) and Law (1\%). 
Figure 2: Awareness of majors and intention to study, of respondents starting their first semester at Zayed University $(n=407)$. Red: number of respondents who listed the major first among up to four they intend to study. Green: number of respondents who considered taking the major, but listed another major first. Blue: number of respondents who listed the major as being available at Zayed University, but were not considering it for themselves.

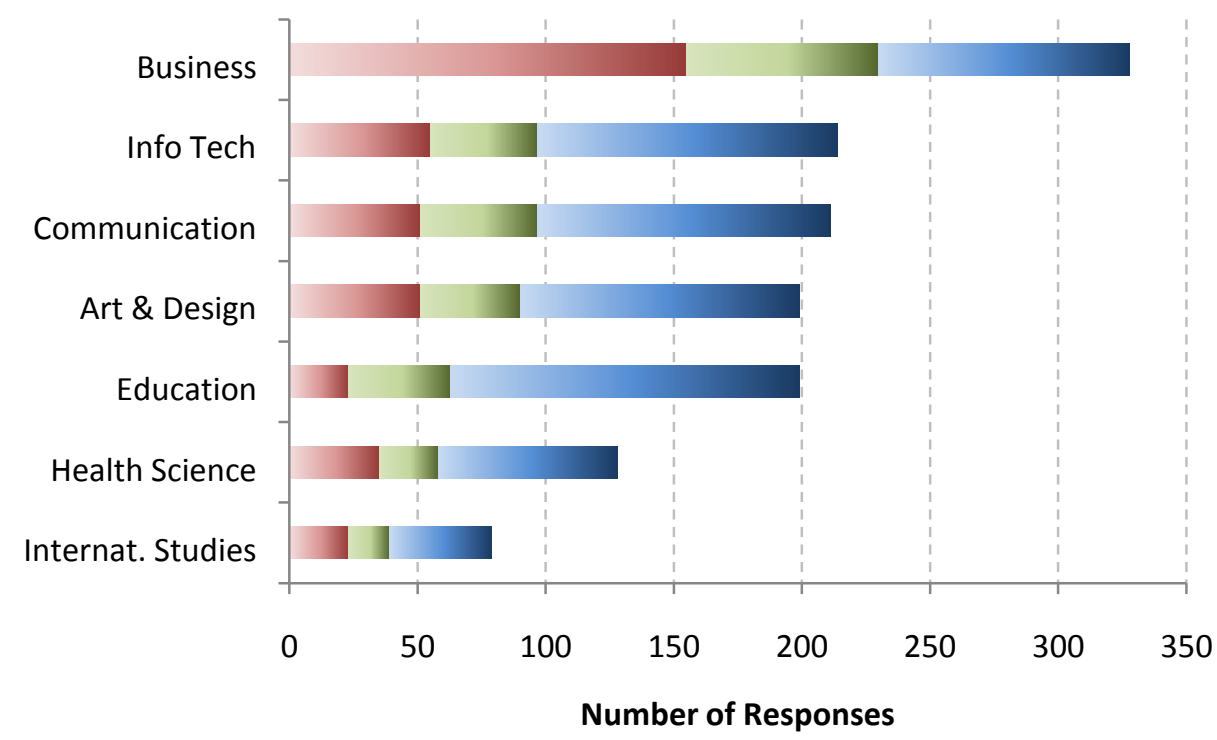

\section{Perceptions of Majors}

Students were asked to rank each major for potential salary, ease of finding a job, and social status (Figure 3). In the same question, we also asked students to rank two of the minors, Applied Psychology and Applied Math. The other two minors offered by the university were considered too similar to existing majors to warrant separate data collection. First semester students were asked to list up to 4 majors (or specializations) they were considering taking. Table 1 shows their first choice, the percent of students who listed just that major, and the percent of students who also listed Business, or a Business specialization.

Respondents were aware of Business and its concentrations far more than any other major, and were far more likely to choose this major (Figure 2). Business rated highest in terms of salary expectations and job availability, and was equaled only by International Studies in perceptions of social status (Figure 3). Furthermore, Business was the primary competitor for students whose first preference was any of the other majors offered at Zayed University (Table 1). These observations indicate that many students are considering their personal interest, but are being swayed by the perception that Business offers the greatest opportunity for desirable employment. 
Figure 3: Expectations of salary, job availability and social status of first semester Zayed University students, where 3 = average, 5 = very high $(n=407)$.

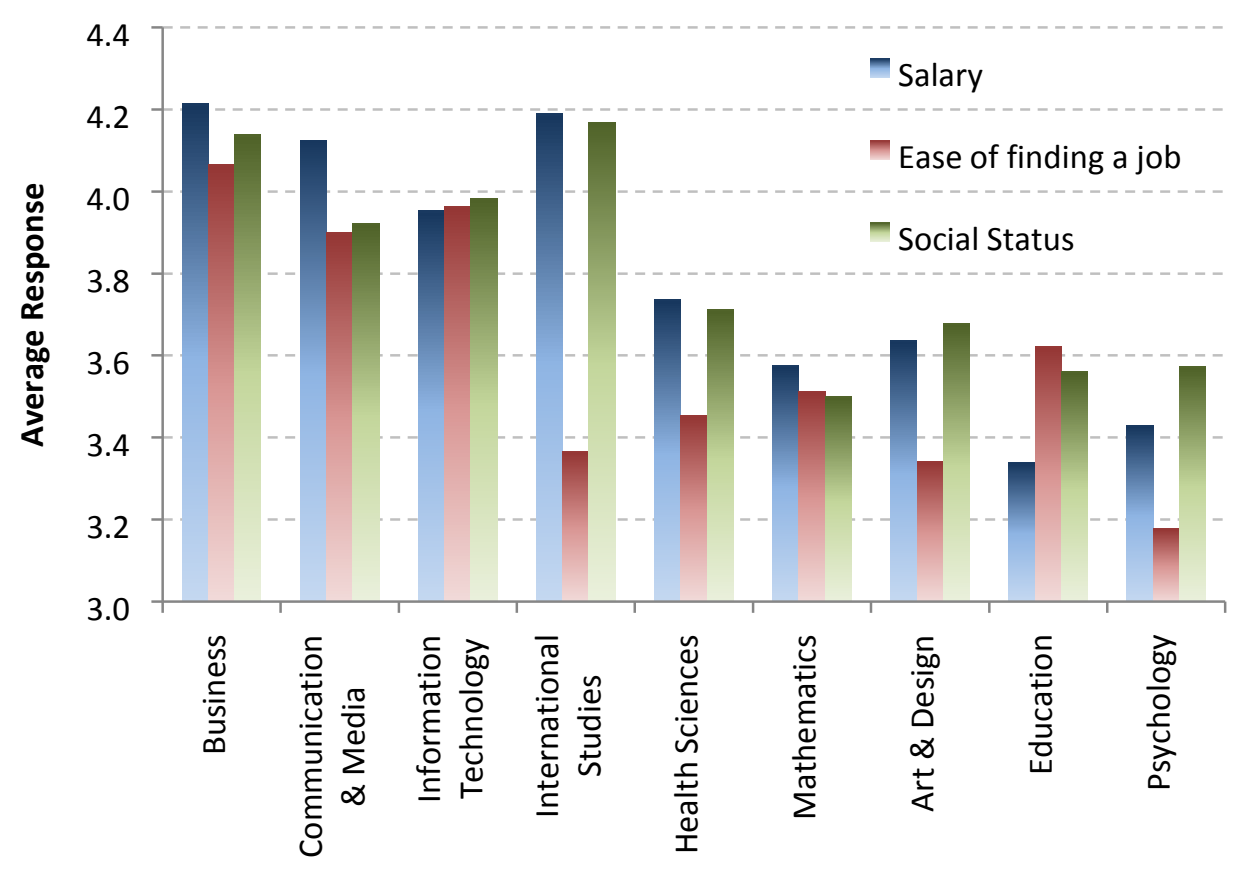

Table 1: Potential majors listed by first semester students.

\begin{tabular}{llll}
\hline Major & $\begin{array}{l}\text { Number who } \\
\text { listed this major }\end{array}$ & $\begin{array}{l}\text { Only one } \\
\text { major listed }\end{array}$ & $\begin{array}{l}\text { Business major } \\
\text { also listed }\end{array}$ \\
\hline Business & 230 & $36 \%$ & $\mathrm{~N} / \mathrm{a}$ \\
Art \& Design & 104 & $21 \%$ & $50 \%$ \\
Communication \& Media & 97 & $22 \%$ & $55 \%$ \\
Information Technologv & 97 & $18 \%$ & $47 \%$ \\
Health Sciences & 70 & $27 \%$ & $57 \%$ \\
Education & 59 & $14 \%$ & $37 \%$ \\
International Studies & 39 & $26 \%$ & $56 \%$ \\
\hline
\end{tabular}

It is not entirely clear why Business holds such an elevated position in students' minds, since most working Emiratis are employed by the government, and most Emirati workforce entrants want to work for the government. According to the UAE Minister of Economy, government employs $88 \%$ of working Emiratis (Al Qassimi, 2006). Of this number, probably $10 \%$ work for government owned companies, and an unknown number supplement their government salary with income from privately owned businesses. In the survey of second semester students, 53\% would prefer a job in government and a further $28 \%$ would prefer a job in a government owned company. This result is similar to a previous study (Walters et al., 2008). Hence, it appears that Emirati youth wish to train for success in the private sector, but then wish to work in the public sector. A possible explanation for its popularity is that the Business major might appeal to a wider range of self efficacies. The Zayed University Business major 
ranges from the math oriented Accounting and Finance specializations, to the more socially oriented Marketing and Human Resource Management specializations.

Students gave similarly high ratings for Information Technology, Communication and Media, and Business (Figure 3), but student interest seems to be biased toward Business (Figure 2). It is possible that the lesser popularity of Information Technology and Communication \& Media is due to a narrower range of specializations in these majors that match with the self-efficacies of fewer students. An interest in Information Technology was associated with a perception that the major leads to a high salary $(p=0.005)$.

The Art \& Design major had reasonably high student awareness and interest, despite being ranked much lower for salary, job availability and social status. Art students were relatively unconcerned about salary ( $p=0.0363)$ or status $(p=0.0455)$. A lower percentage of prospective art students were attending University to secure a job than students thinking of other majors, but this result was not statistically significant. Hence, it seems likely that self-efficacy plays a large part in students choosing this major also.

Education suffers from low perceived salary and social status, though jobs are considered to be of medium availability (Figure 3). Notably, salary expectations for the first job after graduation did not vary by major preference, averaging AED 18000 per month (US\$59 000 per year), suggesting that education salaries are expected to increase less with seniority. Respondents were well aware of the major, but most who were considering taking the major were considering another major more (Figure 2). When asked to list five careers suitable for different categories of people, more than $90 \%$ listed teaching as a career for Emirati women. Hence, it seems safe to conclude that Education retains a high profile among students as a traditional and safe profession, but not one to get rich by.

Students were less aware of Health Science and International Studies, and this translated to fewer respondents considering these majors. The Health Sciences major would probably be more popular if it could become more associated with medicine in the minds of students, especially because students believe the health sector is a suitable place for Emirati women to be employed, though mainly as a doctor (listed by $64 \%$ of students) rather than as a healthcare worker or nutritionist. In fact, when asked to list the majors they would like to see introduced to the University, the most common responses were Engineering (33\% of respondents), Medicine (25\%) and Law (23\%). Several other health professions were also listed with lesser frequency (e.g.; pharmacy, dentistry and laboratory work). The majority of prospective Health Sciences students are pursuing higher education because they want to learn. Prospective students of Health Sciences and Education were more concerned with family expectations than students who wish to pursue other majors. This reaffirms that these two fields are viewed by Emiratis as culturally appropriate fields for women to work in.

Students rated International Studies as having high salary and status, but low job availability (Figure 3). Prospective International Studies students ranked its status as 'very high' much more frequently than others $(p=0.0027)$. Interest in this major was highly correlated with a desire to work for federal government $(p=0.0001)$, indicating that students associate the major with federal politics and diplomacy. Hence, the major would probably see more recruits if its social sciences aspects were better communicated.

\section{Conclusions}

This study has clear implications for the marketing of higher education within the UAE. Majors that directly relate to Business, Medicine, Law, or Engineering are likely to receive much greater interest, 
based on Emirati societal perceptions of these disciplines. The Health Sciences major offered by Zayed University is no substitute for Medicine. Business, on the other hand, remains popular despite defying logical progression from study to preferred employment. Education (teaching primary and secondary levels) remains a socially acceptable choice for Emirati women, but it is perceived to have low social status and salary. The International Studies major has limited intake, in part because Emirati youth are unaware of its value in careers that are not part of federal government.

Our findings do not support substantial institutional assistance for students to select their major, since the influence of the immediate family far exceeds non-family. Marketing efforts are therefore more likely to be effective if they are aimed at the Emirati community, rather than the entering student body. Nevertheless, the average entering student could name fewer than half of the seven available majors, suggesting that they had inadequately explored their University options. The importance of the secured gender-separated environment is also called into question from the students' point of view, though it may still be important for the family of the student.

Reasons for the dominance of Business among student perceptions can only be hypothesized from this study. One possible reason is that the major is better understood by Emirati families, such that Emirati parents are more likely to suggest it and Emirati employers are more likely to hire its graduates. Another possible reason is that students are more confident in their ability to succeed in the discipline, i.e.; they have greater academic self concept. Graduate employment data is required to determine how closely student choices align with job market realities. Further research in the project reported here however, is expected to focus on academic self concept for different majors, and contextual supports and barriers.

\section{References}

Al-Qassimi, S. L. (2006, 7 June). Attracting \& Retaining Nationals in the GCC region. Paper presented at the Human Resources \& Training Breakfast Club, Dubai Knowledge Village.

Al-Taboor, A. (2008, 24 February). History of Education. Retrieved 30 October, 2009, from http://www moe govae

Archer, L., Hutchings, M., \& Ross, A. (2003). Higher education and social class. Issues of exclusion and inclusion. London: RoutledgeFalmer.

Bandura, A. (1977). Social learning theory. New Jersey: Prentice Hall.

Brooks, R. (2004). 'My mum would be as pleased as punch if I actually went, but my dad seems a bit more particular about it': paternal involvement in young people's higher education choices. British Educational Research Journal, 30(4), 495-514.

Crabtree, S. A. (2007). Culture, gender and the influence of social change amongst Emirati families in the United Arab Emirates. Journal of Comparative Family Studies, 38(4).

Holland, J. (1997). Making vocational choices: A theory of vocational personalities and work environments (3 ed.). Lutz, Florida: Psychological Assessment Resources Inc.

IMF. (2005). United Arab Emirates: Selected Issues and Statistical Appendix. Washington: International Monetary Fund.

Lent, R. W., Brown, S., \& Hackett, G. (1994). Toward a unifying social cognitive theory of career and academic interest, choice, and performance. Journal of Vocational Behavior, 45(1), 79-122. 
Nelson, C. (2004). UAE national women at work in the private sector: Conditions and constraints. Dubai, UAE: Trident Communications.

Tedad. (2006). Preliminary Results of Population, Housing and Establishments Census 2005, United Arab Emirates. Abu Dhabi: United Arab Emirates Ministry of Economy.

Walters, T., Mourtada-Sabbah, N., Al Mutawa, M., \& Fox, J. W. (2008). In their Own Words: Women Entering the Workforce in the UAE. Journal of Social Affairs, 25(97), 11-45.

\section{Authors}

David Gallacher is an Assistant Professor at Zayed University, where he has been an academic advisor and teacher of first year experience courses for six years. He holds a Ph.D. in plant genetics from James Cook Universitv, Australia, and has also conducted research on UAE rangeland ecology. Contact: David.Gallacher@zu.ac.ae

Angela Skuba is an instructor and advisor at Zayed University, where she has been teaching for the past five years. She holds an M.A. in Middle Eastern Women's Studies from the University of Durham, U.K., and a B.A. with First Class Honours in Women's Studies from the University of Alberta, Canada.

Roudha Al-Bahri is employed as a part-time research assistant on the project that produced this research; she is also an undergraduate student in the Zayed University College of Education. 